\title{
ANALYSIS OF CERAMIC COMPOSITES BY 3D MICROTOMOGRAPHY
}

\author{
Thomas Lüthi* and William A. Ellingson** \\ *Swiss Federal Laboratories for Materials Testing and Research (EMPA), \\ Ueberlandstrasse 129, CH-8600 Dübendorf, Switzerland \\ **Argonne National Laboratory \\ Materials and Components Technology Division, \\ 9700 South Cass Avenue, Argonne, IL 60439-4838, U.S.A.
}

To be published in the Proceedings of the 4th International Symposium on

Ceramic Materials and Components for Engines, June 10-12, 1991 ,
Göteburg, Sweden

\begin{abstract}
This report was prepared as an account of work sponsored by an agency of the United States Government. Neither the United States Government nor any agency thereof, nor any of their employees, makes any warranty, express or implied, or assumes any legal liability or responsibility for the accuracy, completeness, or usefulness of any information, apparatus, product, or process disclosed, or represents that its use would not infringe privately owned rights. Reierence herein to any specific commercial product, process, or service by trade name, trademark. manufacturer, or otherwise does not necessarily constitute or imply its endorsement, recommendation, or favoring by the United States Government or any agency thereof. The views and opinions of authors expressed herein do not necessarily state or reflect those of the United States Government or any agency thereof.
\end{abstract}

Work sponsored by U.S. Department of Energy, Assistant Secretary for Conservation and Renewal Energy, Transportation Systems, Office of Advanced Materials Program, Assistant Secretary for Fossil Energy, and the Swiss Federal Laboratories for Materials and Research (EMPA), Dubendorf,
Switzerland. 


\title{
ANALYSIS OF CERAMIC COMPOSTTES BY 3D MICROTOMOGRAPHY
}

\author{
THOMAS LÜTHI * and WILLIAM A. ELLINGSON ** \\ * Swiss Federal Laboratories for Materials Testing and Research (EMPA), \\ Ueberlandstrasse 129, $\mathrm{CH}-8600$ Dübendorf, Switzerland \\ ** Argonne National Laboratory, Materials and Components Technology Division, \\ 9700 South Cass Avenue, Argonne, IL 60439-4838, U.S.A.
}

\section{KEY WORDS}

nondestructive testing

3D microtomography

ceramic composites

multidirectional cloth reinforcement

density variations 


\title{
ANALYSIS OF CERAMIC COMPOSITES BY 3D MICROTOMOGRAPHY
}

\author{
THOMAS LÜTHI * and WILLIAM A. ELLINGSON ** \\ * Swiss Federal Laboratories for Materials Testing and Research (EMPA), \\ Ueberlandstrasse 129, CH-8600 Dübendorf, Switzerland \\ ** Argonne National Laboratory, Materials and Components Technology Division, \\ 9700 South Cass Avenue, Argonne, IL 60439-4838, U.S.A.
}

\begin{abstract}
In the first part we describe the use of 3D X-ray microtomography for the analysis of density distributions inside and between cold pressed green state whisker reinforced $\mathrm{Si}_{3} \mathrm{~N}_{4} / \mathrm{Si}_{3} \mathrm{~N}_{4}$ bending test specimens. The differences between a changing content of whisker volumes ( 0 to $35 \%$ ) show a sharp density reduction between 10 and $15 \%$. This agrees with previous research which shows that maximum density is achieved between 10 and $15 \%$ whisker loadings. Since density is directly related to fracture strength, microtomography may be useful as strength prediction.

In the second part we describe the use microtomography combined with image processing, especially a 2D FouRIER transform, for the analysis of cloth direction distributions in multidirectional reinforced chemical vapor infiltrated (CVI) SiC / $\mathrm{SiC}$ test components. The SiC fibers were NICALONTM and were oriented 30,60 , and $90^{\circ}$. In laying up the cloth, orientations may not be maintained and this impacts the mechanical properties. Use of microtomography with image processing may allow mechanical property variations to be established.
\end{abstract}

\section{INTRODUCTION}

The use of $2 \mathrm{D}$ or $3 \mathrm{D}$ ccmputed tomography for the inspection of ceramics was reported earlier [1 - 3]. Often, however, the primarily aim of these works was to find flaws or irregularities and according to the nature of ceramic materials, microtomographic systems were used [4 - 5]. In terms of spatial resolution the todays possibilities are in the region of $50 \mu \mathrm{m}$ or even less. With 3D cone beam tomographs this resolution is also to be achieved in the third direction, however, not without more sophisticated and therefore time consuming algorithms and only for a very small aperture [6]. According to the setup of 3D cone beam tomographs in terms of contrast discrimination, 2D tomographs are superior for the moment. The coming 
design of data acquisition and especially computing hardware could change this situation. The recent works in 3D NMR imaging of ceramics [7] could emphasize this effort.

\section{METHODS AND MATERIALS}

\section{D Computed Tomographic System}

Measurements were carried out on a third generation 3D cone beam computed tomographic system which schematic setup is given in figure 1. The source is a 160 $\mathrm{kV}$ microfocus X-ray tube (IRT HOMX 161) with a spot size of 10 to $20 \mu \mathrm{m}$ diameter. The detector system contains of a trifield $\left(9,6,4.5^{\prime \prime}\right)$ image intensifier and a Sony XC $57512 \times 512$ CCD-camera (8 bits). Using a third generation CT-method this setup e.g. would allow a pixelsize of $50 \mu \mathrm{m}$ for an object of $20 \mathrm{~mm}$ diameter (geometric magnification $10 \mathrm{x}$ ). For the motor control and the data acquisition we used an IBM PC/AT with an accelerated frame grabber board. The next calculations up to the rough images were made either on a VAX 8700 or on a SUN 4 workstation. For the image processing and display, finally, we used a Macintosh llfx.

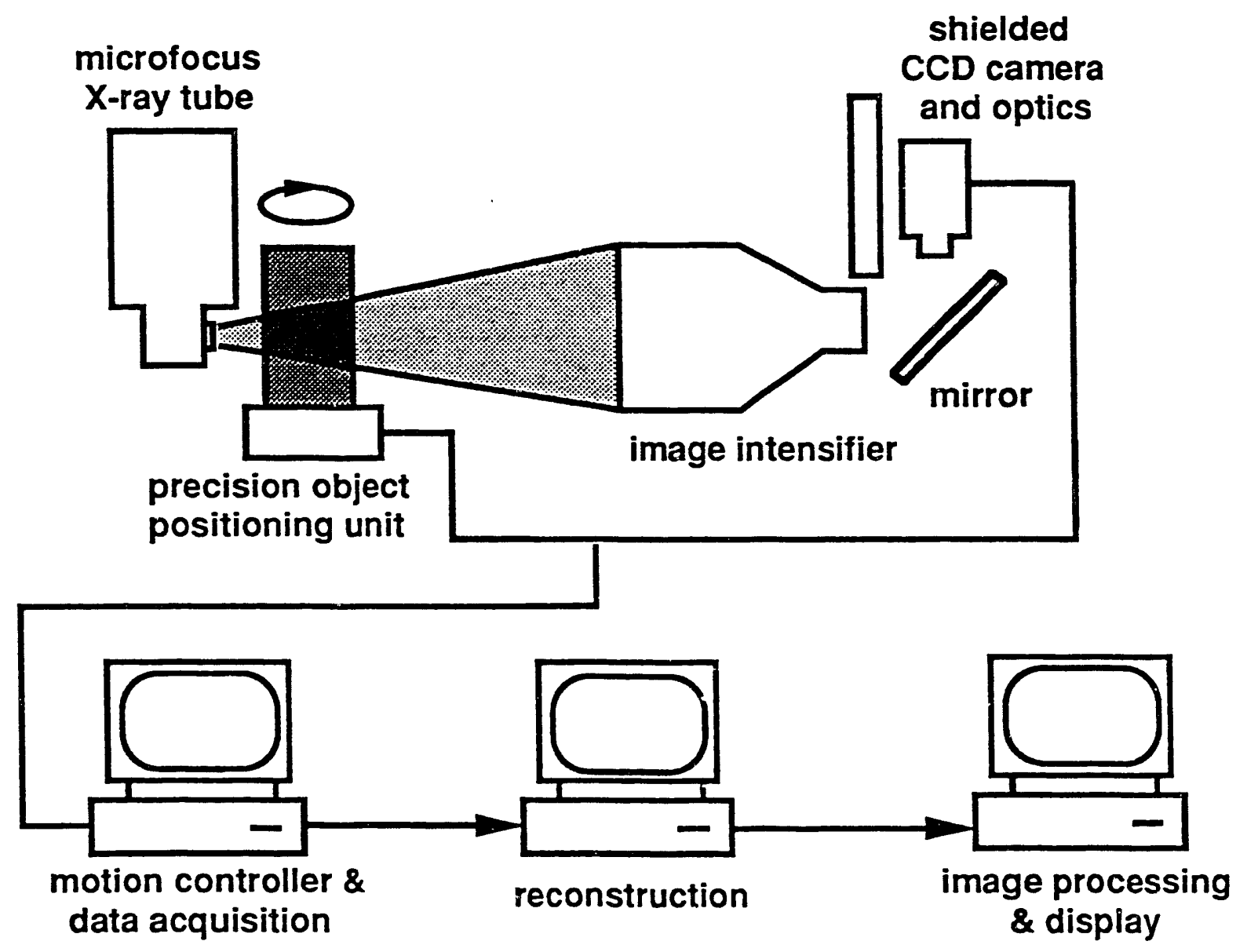

Figure 1. Schematic setup of the used 3D tomographic system. For reasons of clarity, the aperture is shown too large. 


\section{Specimens}

The first set consisted of $\mathrm{Si}_{3} \mathrm{~N}_{4} / \mathrm{Si}_{3} \mathrm{~N}_{4}$ whisker reinforced bending-test specimen (about $50 \times 6 \times 3 \mathrm{~mm}$ ) in green state. The whiskers had a diameter of 0.6 to $1.0 \mu \mathrm{m}$ and a length of about 10 to $15 \mu \mathrm{m}$. Their distribution was more or less randomily but certainly influenced by the cold pressing manufacturing process. The volume content of the whisker loadings ranged from 0 to $35 \%$. For this preliminary work, where we had to learn how to handle these delicate samples, we took already broken ones. But the aim of this method certainly is to do this examination before mechanical tests are made.

The second set, however, consisted of multidirectional cloth reinforced SiC I $\mathrm{SiC}$ composites. These samples have been produced at Oak Ridge National Laboratory, using a chemical vapor infiltration (CVI) technique which combines the thermal gradient and pressure gradient processes [8]. The SiC fibers were NICALON'M and were oriented 30,60 , and $90^{\circ}$. The objects had a shape like a disk with a diameter of about $45 \mathrm{~mm}$ and a height of approximately $12 \mathrm{~mm}$.

In each case the materials of the matrix and of the reinforcement are the same, so that resulting gray levels are pretty much related to the density.

\section{RESULTS}

\section{$\mathrm{Si}_{3} \mathrm{~N}_{4} / \mathrm{Si}_{3} \mathrm{~N}_{4}$ Samples}

For these samples the gray level differences between different whisker loadings was examined. Figure 2 shows one slice of each sample. Already here a sharp reduction between 10 and $15 \%$ is clearly visible.

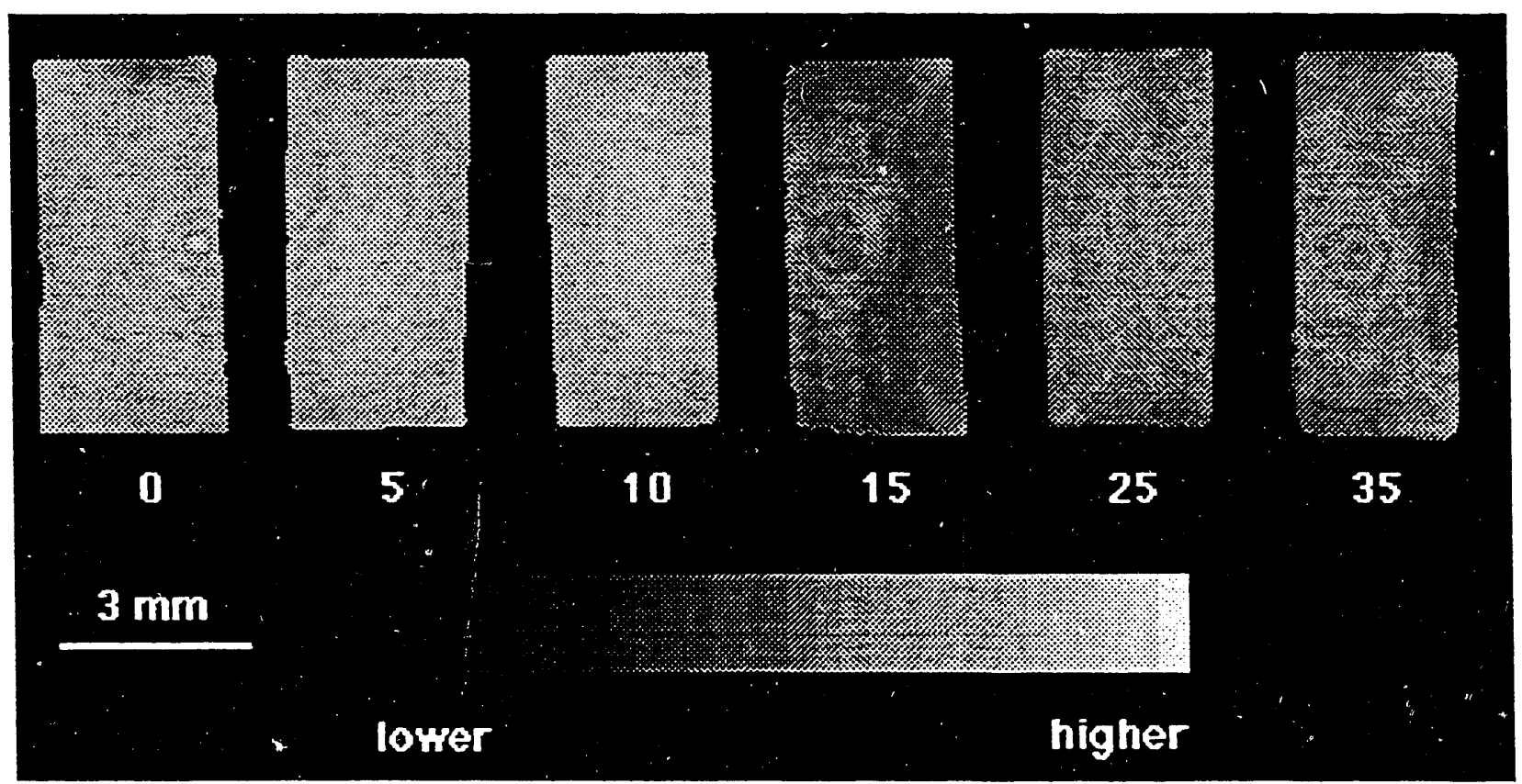

Figure 2. Differences in gray levels for different whisker loadings. 
To save calculation time, the images were reconstructed with $256 \times 256$ pixels (each with two samples), so that a pixelsize of $40 \mu \mathrm{m}$ is resulting.

To avoid edge effects, the gray levels were measured in the central region of the slices, covering about $50 \%$ of the total area. The standard deviation for one slice is always about 3 to 4 grays, the differences of the mean values of different slices of the same sample are about the same. No differences of these statements are to be found between the unloaded $(0 \%)$ and the loaded samples. The reduction between 10 and $15 \%$ is significant; the lowest gray level found in all slices of the 10 $\%$ sample is still 15 grays higher than the highest of the $15 \%$ sample (figure 3 ).

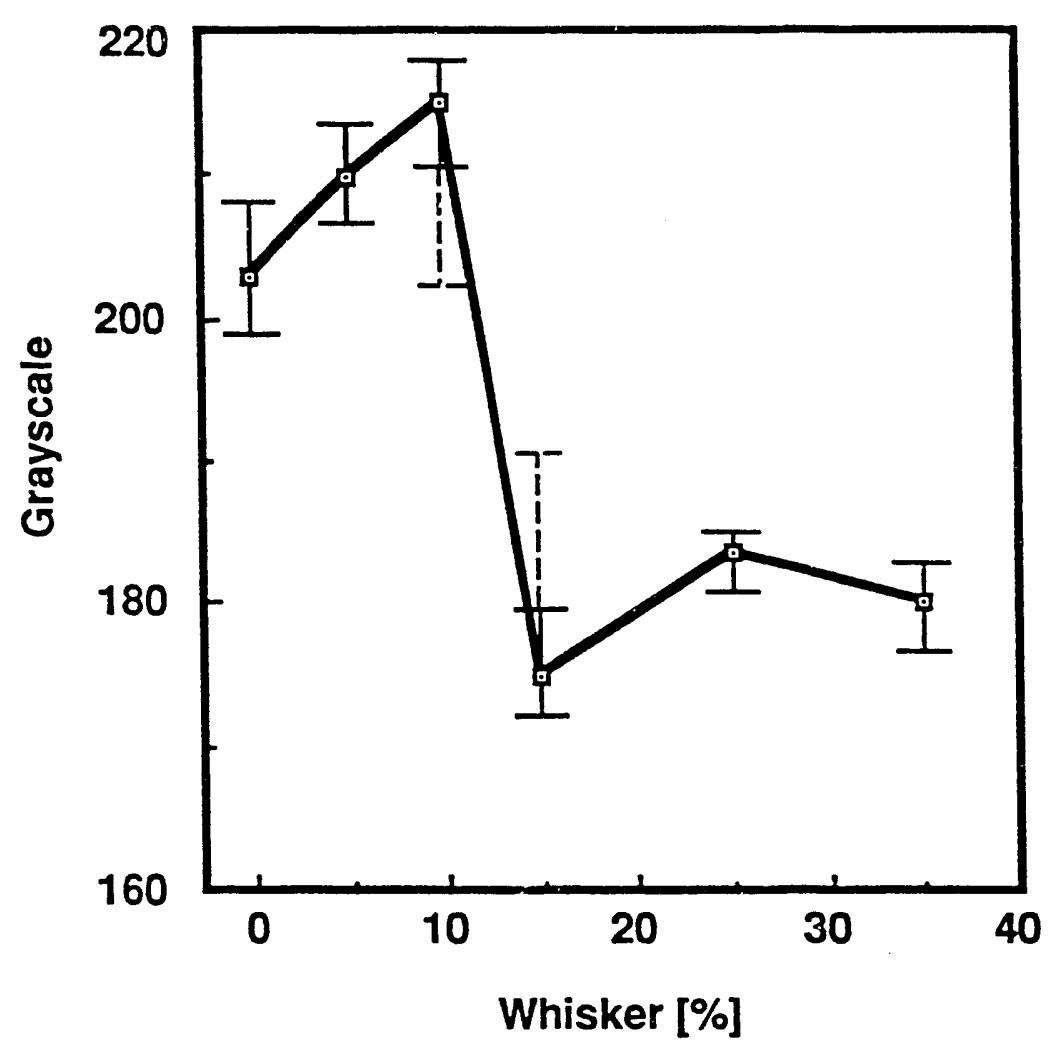

Figure 3. Mean gray levels over seven slices, highest and lowest mean value of the single slices and maximum and minimum gray level of single pixels for 10 and $15 \%$ (dotted line).

\section{SiC / SiC Samples}

These objects were much larger and in this case the best possible pixelsize would have been about $100 \mu \mathrm{m}$. For the examination of the reinforcement structure, however, a pixelsize of about $200 \mu \mathrm{m}$ was sufficient. Figure 4 shows a slice through two different samples (261 and 262). Four effects are recognizable: in both cases the density in the center of the samples is higher than at their periphery (the usual beam-hardening effect would show just opposite characteristics). From the gray level curves through the center of the objects, it is to assume that the density gradient is pretty linear but different for both samples. The same curves also show a suf "structure due to the reinforcement. 

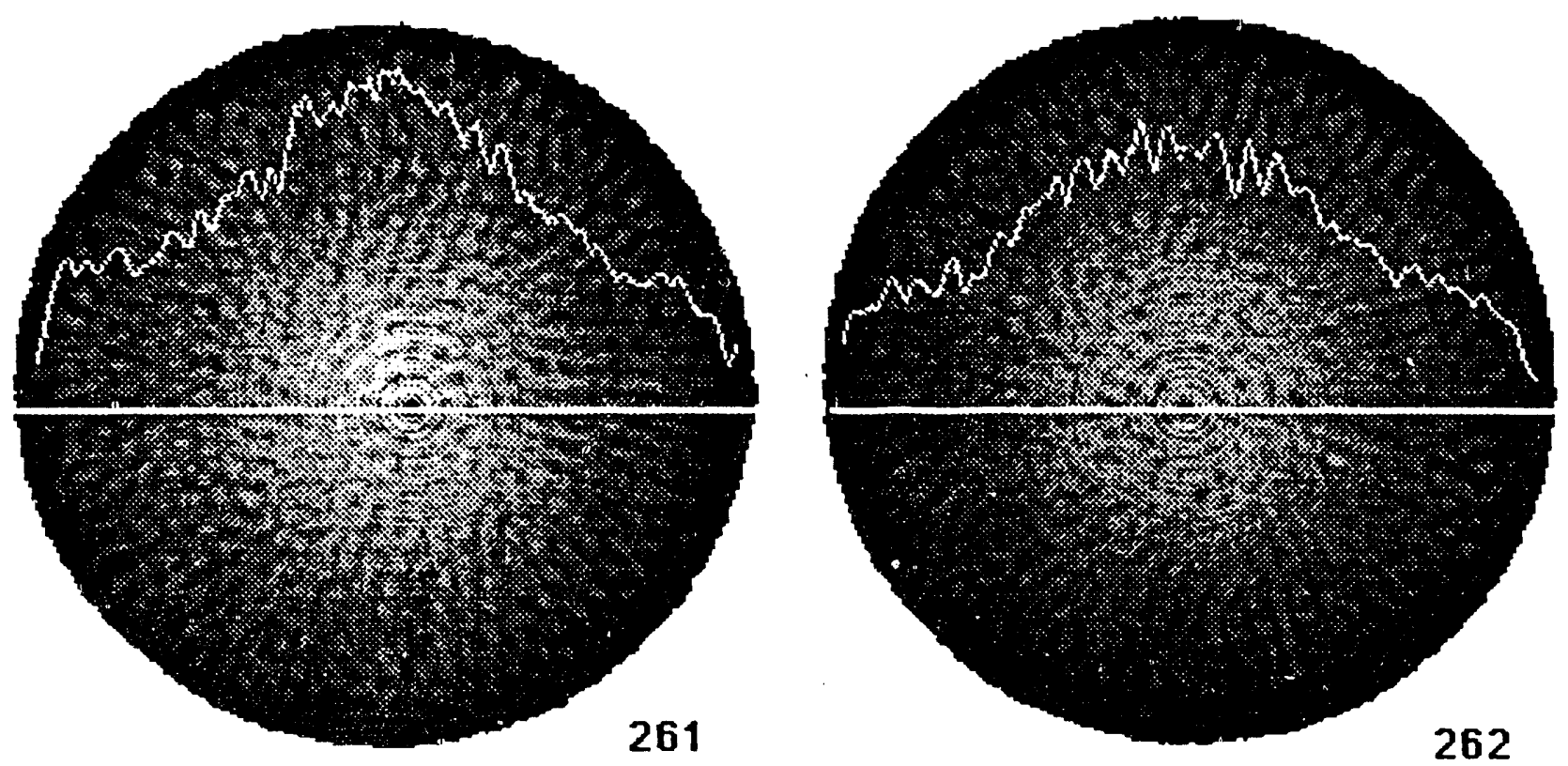

$10 \mathrm{~mm}$

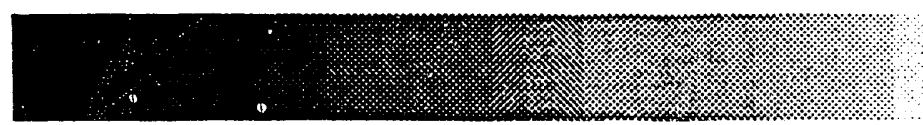

lower

higher

Figure 4. Variations of the density inside of two SiC / SiC samples.

Each tomogramm contains $256 \times 256$ pixels, the air is cut.

It is not possible to make statements about the reinforcement structure looking at the slices in the time domain. After a 2D fast FouRIER transform (FFT), however, this structure becomes clearly visible (figure 5). As the height of each slice is about $1 \mathrm{~mm}$, all six directions $\left(30,60\right.$ and $90^{\circ}$ and perpendicular to these, respectively) are represented. In the frequency domain they are represented as points at a corresponding frequency, in this case $1.5 \mathrm{~mm}$ per cycle. As figures in the frequency domain are radially symmetric, a total of twelve points is to become detected.

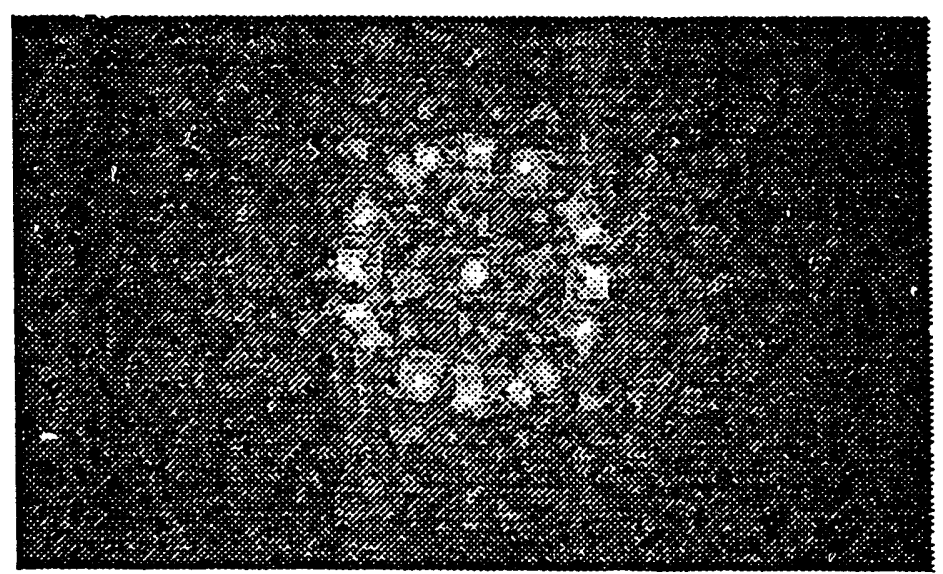

Figure 5. ?D FFT of a slice; the points represents the reinforcement structure at about $1.5 \mathrm{~mm}$ per cycle, the upper and lower part of the image is cut. 
Examining the structure of the reinforcement using this kind of image processing, several effects are to be found. The radial extension of the points and therefore differences in the directions of the cloths are not always the same; for some slices even separations in one direction are found (figure 6). To be able to measure these radial extensions equally, the images were transformed into binary versions.

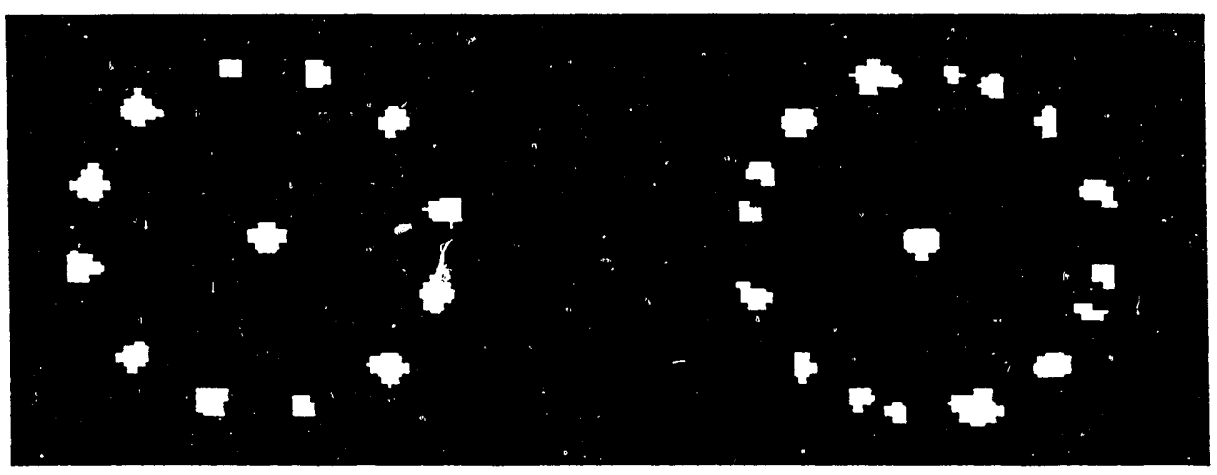

Figure 6. Two basic types of 2D FFTs; left side: normal reinforcement, difference always about $30^{\circ}$; right side: separation in one direction.

The results of these measurements for seven slices are given in figure 7 , the direction of $0^{\circ}$ is arbitrary as it is influenced on the orientation of the object on the CT system. The trend of these graphs shows that the directions of the layers are not strictly maintained and that the relation between one direction and its perpendicular direction is not always very strong (e.g. sample 261 , directions 60 and $150^{\circ}$, respectively).
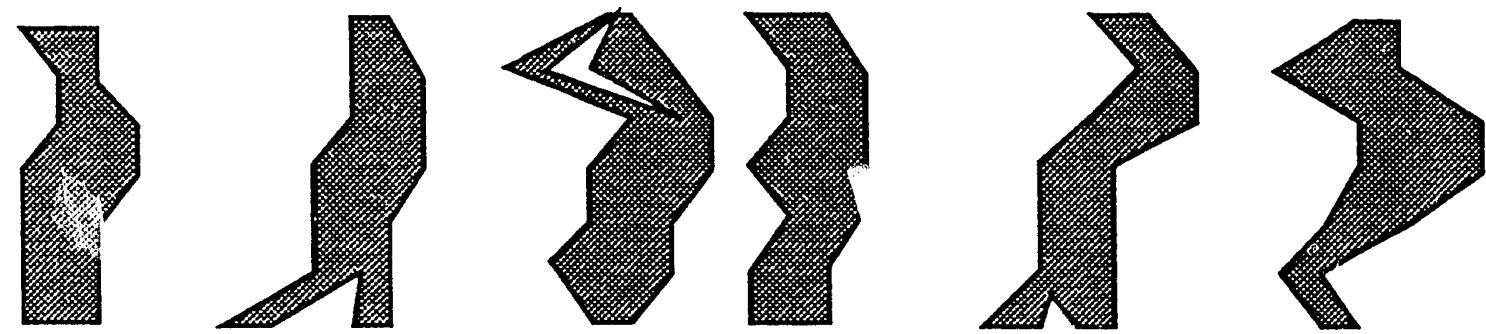

261
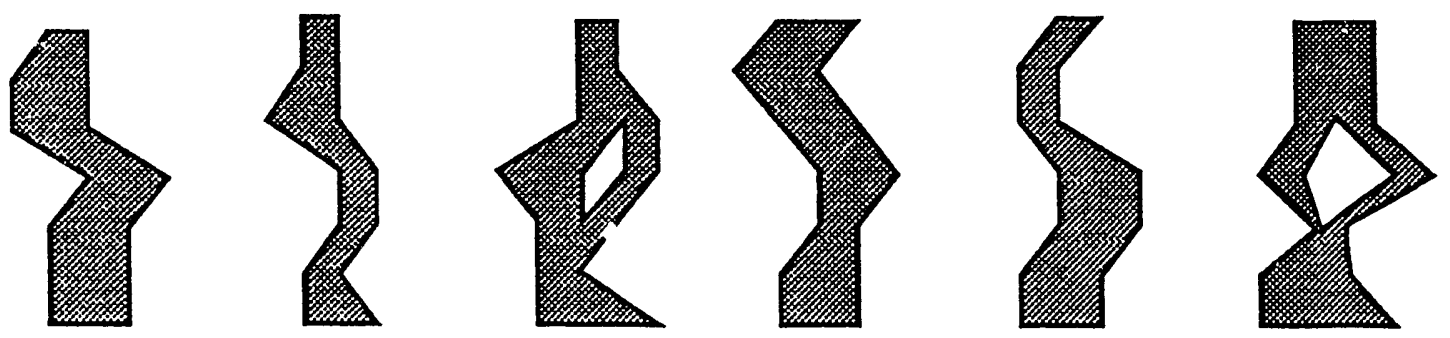

262

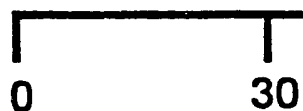

60

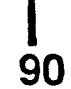

120

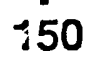

Figure 7. Directions of the reinforcement structure of the multidirectional cloth reinforced samples; each slice has a height of about $1 \mathrm{~mm}$. 


\section{DISCUSSION}

In the first examination a clear density reduction which for similar materials is also reported by other authors [9] was found using 3D microtomography. Inside each sample certain density variations can be found which are due to the cold pressing manufacturing process. Because of that and of small density differences we can clearly distinguish between a high density region ( $0-10 \%$ whisker loading) and a low density region ( $\geq 15 \%$ whisker loading) but only hardly inside of these. The clear difference between measurements on the $10 \%$ and the $15 \%$ samples leads to the statement that there are no whisker enrichments with dimensions nearly the examined voxel $(1000 \times 40 \times 40 \mu \mathrm{m})$.

In the second examination it was possible to find variations in multidirectional cloth reinforcements in several heights of the samples. Even if the radial accuracy is not more than $5^{\circ}$, differences are clearly shown. The demonstrated weak relation between perpendicular directions of the reinforcement let us assume that certain cloths are under residual stress which would impact their mechanical properties. For flat objects this technique can also be used directly with radiographic images, for larger object, however, the information in the third dimension would be missing and separations or variations would not become detected.

\section{CONCLUSIONS}

X-ray microtomographic systems may not only be used for inspection of ceramics with the aim to find flaws or irregularities but also as an aid for process control. Even if the contrast discrimination of a todays $3 D$ system is lower than that of a 2D system it is suitable, especially for the second purpose.

In two examples we have shown the use of 3D microtomography for strength prediction and, combined with sophisticated image processing, for establishing mechanical property variations.

\section{ACKNOWLEDGEMENTS}

Work was partially supported by U.S. Department of Energy, Office of Fossil Energy, Advanced Research and Technology Development Materials Program under Contract W-31-109-Eng-38.

\section{REFERENCES}

1 RICE, R.W.: "Toughening in ceramic particulate and whisker composites", Ceram. Eng. Sci. Proc. 11 [7-8] (1990) pp. 667 - 694

2 Ellingson, W.A., Vannier, M.W. and Stinton, D.P.: "Application of X-ray computed tomography to ceramic/ceramic composites" Symp. on characterization of advanced materials, Monterey, CA (1987) 
3 Engler, Ph., Friedman, W.D., Skarpness, B.O. and Ohnsorg, R.: "Process control for ceramics using CT of prefired and fired parts", Conf. on NDE of modern ceramics, ASNT, Columbus, OH (1990) pp. $16-20$

4 YANCEY, R.N., KLIMA, S.J. and SMITH, J.A.: "High resolution CT of modern ceramics", Conf. on NDE of modern ceramics, ASNT, Columbus, OH (1990) pp. 126 130

5 Reiter, H., Maisl, M., Pangraz, S. and Arnold, W.: "High resolution X-ray and ultrasonic methods for the nondestructive evaluation of modern ceramics", Conf. on NDE of modern ceramics, ASNT, Columbus, OH (1990) pp. 64 - 68

6 Rizo, Ph, Grangeat, P., Sire, P., Lemasson, P. and Melennec, P.: "Comṕarison of two 3D X-ray cone beam reconstruction algorithms ivith circular trajectory", to be published, $\underline{j}$. Opt. Soc. Amer.

7 Dieckman, S.L., Rizo, P. and Gopalsami, N.: "3D NMR and X-ray imaging of solid state materials" in "Advanced tomographic imaging methods for the analysis of materials", Mat. Res. Sec. Symp. Proc. Series Vol. 17 (1990)

8 Stinton, P.D., CAputo, A.J. and Lowden R.A.: "Synthesis of fiber-reinforced SiC composites by CVI", Amer. Ceram. Soc. Bull. 65 [2] (1986) pp. 326 - 335

9 Kodama, $\mathrm{H}$. and MiYosHI, T.: "Fabrication and properties of $\mathrm{Si}_{3} \mathrm{~N}_{4}$ composites reinforced by SiC whiskers and particles", Ceram. Eng. Sci Proc. 10 [9-10] (1989) pp. 1072 - 1082 

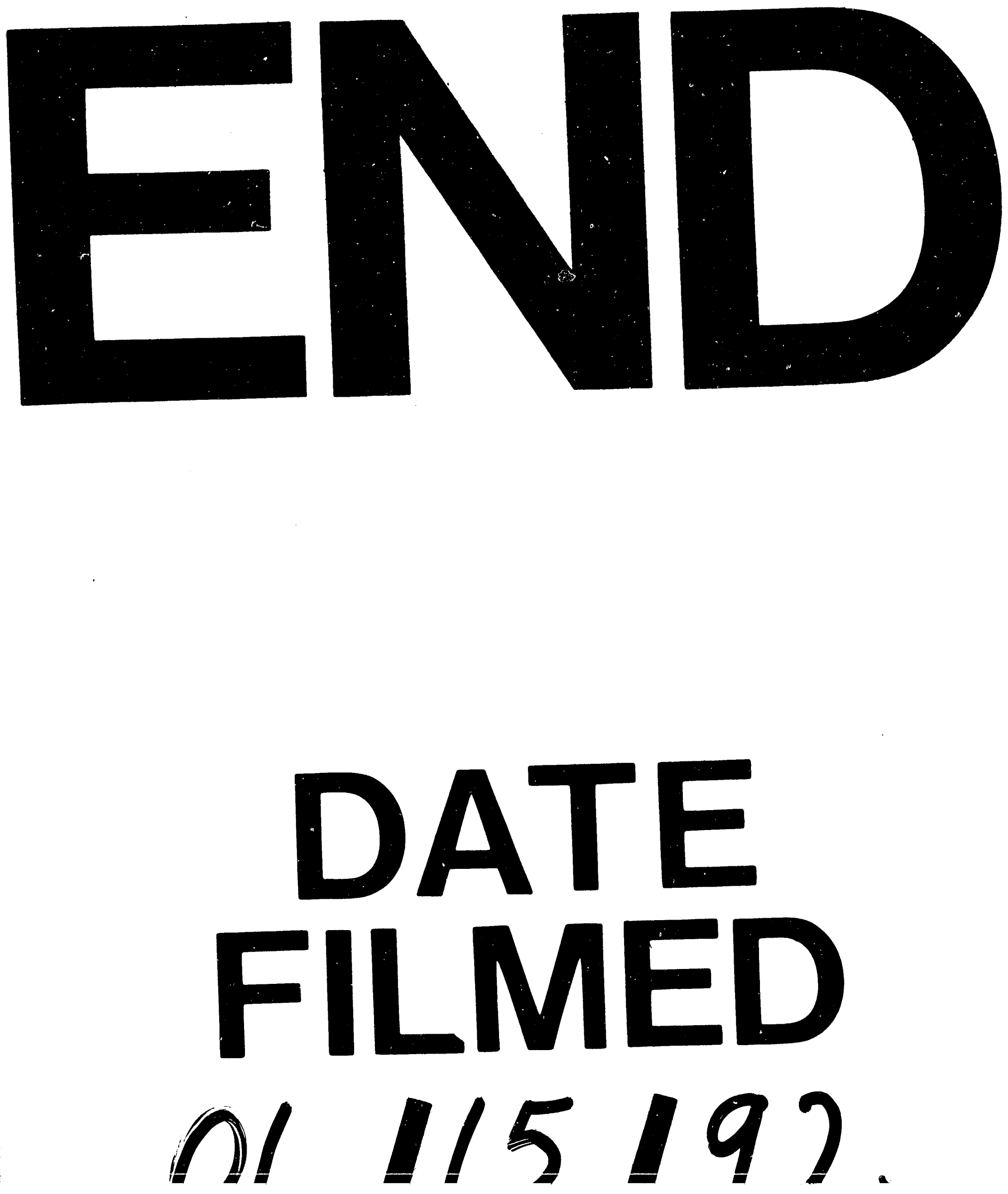
